\title{
Drug interactions of anti-microbial agents used in hematopoietic stem cell transplantation ${ }^{1}$
}

\author{
Rosimeire Barbosa Fonseca Guastaldi² \\ Silvia Regina Secoli ${ }^{3}$
}

This study analyzed potential drug interactions (PDIs) of antimicrobials used in patients of hematopoietic stem cell transplantation and identified associated factors. The sample consisted of 70 patients admitted to a hospital in São Paulo. The PDIs were analyzed through the consultation of the Drug Interactions Facts and Drug Interactions Handbook. Descriptive statistics and logistic regression were used. Half of the sample was exposed to 13 PDIs, which occurred with fluconazole $(53.8 \%)$, ciprofloxacin $(30.8 \%)$ and sulfamethoxazoletrimethoprim (15.4\%). Most (92.3\%) were of moderate severity, with good evidence $(61.6 \%)$, early delayed effect $(61.5 \%)$ and need to have their therapy monitored $(76.9 \%)$. Patients with four or more medications $(p<0.001)$, aged between $40-49$ years of age ( $p$ $<0.001)$, and being male $(p<0.001)$ were associated with PDIs. A PDI may result in adverse outcomes, impacting patients' morbidity and mortality. Combination regimens can be safe, provided there is careful monitoring by professionals involved in care delivery.

Descriptors: Drug Interactions; Oncologic Nursing; Nursing Assessment.

\footnotetext{
${ }^{1}$ Paper extrated from Master's Dissertation "Interações medicamentosas potenciais: um estudo dos antimicrobianos utilizados em pacientes submetidos a transplante de medula óssea" presented to Escola de Enfermagem, Universidade de São Paulo.

${ }^{2}$ RN, M.Sc. in Nursing, Professor, Universidade Paulista, SP, Brazil. E-mail: meire.2310@ig.com.br.

${ }^{3}$ RN, Ph.D. in Nursing, Associate Professor, Escola de Enfermagem, Universidade de São Paulo, SP, Brazil. E-mail secolisi@usp.br.
}

Corresponding Author:

Silvia Regina Secoli

Universidade de São Paulo. Escola de Enfermagem

Av. Dr Enéas de Carvalho Aguiar, 419

Bairro: Cerqueira César

CEP: 05403-000, São Paulo, SP, Brasil

E-mail: secolisi@usp.br 


\title{
Interações medicamentosas de antimicrobianos utilizados em transplante de células-tronco hematopoéticas
}

Neste estudo, analisaram-se as interações medicamentosas potenciais (IMP) de antimicrobianos, usados em pacientes submetidos a transplante de células-tronco hematopoiéticas e foram identificdos os fatores associados às IMPs. A casuística foi composta por 70 pacientes internados em hospital do município de São Paulo. As IMPs foram analisadas através da consulta ao Drug Interactions Facts e Drug Interactions Handbook. Na análise dos dados, utilizou-se estatística descritiva e regressão logística. Metade da amostra foi exposta a 13 IMPs, que ocorreram com fluconazol $(53,8 \%)$, ciprofloxacina $(30,8 \%)$ e sulfametoxazol+trimetoprima $(15,4 \%)$. A maioria $(92,3 \%)$ apresentou gravidade moderada, início de efeito demorado $(61,5 \%)$ e necessidade de monitorar a terapia (76,9\%). Quatro ou mais medicamentos $(p<0,001)$, idade 4049 anos $(p<0,001)$, sexo masculino $(p<0,001)$ foram associados ao risco de IMP. As implicações das IMPs podem resultar em desfechos adversos, causando impacto na morbimortalidade do paciente. Os regimes combinados podem ser seguros, desde que haja monitoramento criterioso por parte dos profissionais envolvidos no cuidado.

Descritores: Interações de Medicamentos; Enfermagem Oncológica; Avaliação em Enfermagem.

\section{Interacciones medicamentosas de antimicrobianos utilizados en trasplante de células madre hematopoyéticas}

\begin{abstract}
El estudio analizó interacciones medicamentosas potenciales (IMP) de antimicrobianos usados en pacientes sometidos a trasplante de células madre hematopoyéticas e identificó los factores asociados las IMP. La casuística fue compuesta por 70 pacientes internados en un Hospital de Sao Paulo. Las IMP fueron a través de la consulta al Drug Interactions Facts y Drug Interactions Handbook. En el análisis de los datos se utilizó estadística descriptiva y regresión logística. Mitad de la muestra fue expuesta a 13 IMP, que ocurrieron con fluconazol $(53,8 \%)$, ciprofloxacina $(30,8 \%)$ y sulfametoxazol+trimetoprima $(15,4 \%)$. La mayoría $(92,3 \%)$ presentó gravedad moderada, inicio de efecto demorado $(61,5 \%)$ y necesidad de monitorizar la terapia (76,9\%). Cuatro o más medicamentos $(p<0,001)$, edad entre 40 y 49 años $(p<0,001)$ y sexo masculino $(p<0,001)$, fueron asociados al riesgo de IMP. Las implicaciones de las IMP pueden resultar en resultados adversos, causando impacto en la morbimortalidad del paciente. Los regímenes combinados pueden ser seguros, desde que exista monitorización cuidadosa por parte de los profesionales envueltos en el cuidado.
\end{abstract}

Descriptores: Interacciones de Drogas; Enfermería Oncológica; Evaluación de Enfermería.

\section{Introduction}

Drug interactions (DIs) are among the main evitable causes of adverse drug events (ADEs); DIs represent $20 \%$ to $30 \%$ of these and are clinically relevant in $80 \%$ of the cases, especially among elderly individuals ${ }^{(1-2)}$. Even though ADEs accruing from DIs are underreported, they are considered to be a health problem because there are interactions that cause treatment failure in patients without a clinical modification immediately obvious.
DIs occur when a medication (precipitant) interferes in the action of another (object). The first causes alterations in the pharmacokinetics or mechanism of action of the second. Such an event may result in three potential outcomes: to increase or reduce the therapeutic or the adverse effect, or present a response different from what was originally expected from the medication $^{(3-4)}$. 
The DI phenomenon in the hematology-oncology field is still seldom addressed despite the vulnerability of patients cared for in this specialty, particularly those undergoing hematopoietic stem cell transplantation (HSCT). In this type of therapy, the receptor's marrow aplasia is first performed and then, previously treated hematopoietic tissue cells or those from a compatible donor, are intravenously infused to reestablish hematopoiesis ${ }^{(5)}$. Exposure of patients to complex therapeutic regimes consisting of a narrow therapeutic index, toxicity in various potentially interactive organ and antimicrobial systems, association with pharmacokinetics and pharmacodynamic variability, are some of the factors that increase the risk of DI in individuals undergoing $\mathrm{HSCT}^{(6-7)}$.

A study conducted with outpatients with solid tumors found that $27 \%$ of them presented at least one DI, which reached $31 \%$ of patients treated in a hospice care service $^{(8-9)}$. In HSCT patients treated with antifungal medication, $86 \%$ were exposed to at least one DI and $26 \%$ presented one or more ADE related to the identified $\mathrm{DI}^{(7)}$. A Brazilian study conducted in a hematology unit showed that $95.5 \%$ of the sample was exposed to an association of potentially interactive medications in the post-chemotherapy phase ${ }^{(10)}$. In a general hospital, $63 \%$ of the hematological patients with solid tumors presented at least one DI during hospitalization(11). Even though a causal relationship is difficult to establish, the impact of DI can be very relevant. One study indicated that $4 \%$ of deaths identified in hospitalized individuals diagnosed with cancer were related to severe DIs ${ }^{(12)}$.

A review paper addressing DIs in organ transplantation patients, including bone marrow transplantation, reported that antimicrobial medication such as fluconazole, trimethoprim/sulphamethoxazole, acyclovir, and imipenem interact with cyclosporine, one of the most frequently used immunosuppressant medications in $\mathrm{HSCT}^{(13)}$.

This study was conceived considering that antimicrobial medication represent, within the scope of HSCT, an essential therapeutic class for the procedure's success, that many of these are introduced in the conditioning phase to prevent infections, especially those of a fungal nature, and that knowledge of oncologic nurses concerning the impact of DIs, even if potential knowledge, can help in the monitoring of clinical manifestations indicative of DIs. The objectives were to analyze the potential antimicrobial medication DIs in the case of HSCT patients concerning the following aspects: severity, scientific evidence, potential clinical implications, effect onset time, and risk level of mixed therapy, in addition to identifying factors associated with interactions.

\section{Methods}

This cross-sectional and prospective study was conducted in the HSCT ward in the Instituto de Coração [Heart Institute] at the Hospital das Clinicas, University of São Paulo, Medical School. The sample was composed of 70 patients in the conditioning phase on the day prior to bone marrow infusion (day 1 ), regardless of race, diagnosis, age or gender, hospitalized between January and July 2005. Given the fact that the focus of this investigation was antimicrobial medication, which was included in the therapeutic scheme for infection prophylaxis on day 1 according to the facility's protocol and the needs of each patient, we opted for analyzing the therapy medication on this specific day. Patients referred to the intensive therapy unit or those who died on the day of study were excluded.

Data collection proceeded after the project was approved by the Research Ethics Committee (Protocol N01107/04) at the hospital and was carried out in two phases. The first phase included consulting patients' medical files to obtain information about the patients and medications prescribed, from which the following variables were collected: age, gender, diagnosis, HSCT type, type of central catheter, the medication's name, route of administration and time. In the second phase, specific literature was examined to classify DIs, whose variables included: severity, scientific evidence, potential clinical implications, effect onset time, and risk of mixed therapy.

In this study the term 'Potential Drug Interaction' (PDI) was used, which refers to the chance of a given medication altering the intensity of the pharmacological effect of another medication included in the therapy.

PDIs were classified based on studies of renowned authors ${ }^{(3-4)}$. The effects accruing from DIs in the severity degree classified as 'Major' threaten one's life and may cause permanent damage. In 'Moderate' severity, responses may harm patients or increase their time of hospitalization, while effects in 'Minor' severity are mild and consequences may either bother the individual or even pass unnoticed, though additional therapy is required(3).

Five categories were considered to constitution scientific evidence: Established, Likely, Suspected, Possible and Unlikely. Documentation in the category 'established' is included when there is evidence through the occurrence of DI in well-controlled studies. DI is considered 'likely' when it is typical though not clinically 
proved; 'suspected' if DI can occur, if there is some information related to the event though further studies are required. 'Possible' when DI may occur but data are very limited, and 'unlikely' when there is no evidence of alteration of clinical effects in patients ${ }^{(3)}$. Effect onset time refers to the point when an adverse effect appears and DIs are classified as 'fast' (within 24 hours) and 'delayed' (days or weeks)(3).

The risk of mixed therapy was classified into five levels: A - there is no known occurrence of DI; B no therapeutic action is required; $C$ - Monitor therapy; D - Consider changing therapy; and X - Avoid mixed therapy with analyzed agents ${ }^{(4)}$.

The Statistical Package for the Social Sciences (SPSS) program version 13.0 was used in data analysis. Multivariate logistic regression adjusted by gender and age was used to verify any association between the independent variables (gender, age, HSCT type and number of administered medication) and the dependent variable (PDI). The level of significance was fixed at $p<0.05$.

\section{Results}

Most $(97.2 \%)$ of the sample was composed of individuals affected by malignant hematological diseases, submitted to autologous HSCT (65.7\%) and received medication through semi-implanted venous catheters $(94.3 \%)$, as shown in Table 1 . The median age of patients was 36 years old (variation from 10 to 50 years old).

Table 1 - Distribution of sample according to gender, diagnosis, and type of transplantation. São Paulo, SP, Brazil 2005

\begin{tabular}{llc}
\hline \multicolumn{1}{c}{ Variables } & \multicolumn{2}{c}{ Patients $(\mathbf{n}=\mathbf{7 0})$} \\
\cline { 2 - 3 } & $\mathrm{n}$ & $\%$ \\
\hline Gender & 37 & 52.9 \\
Male & 33 & 47.1 \\
Female & & \\
Diagnosis & 27 & 38.6 \\
Lymphomas (HL/NHL) & 21 & 30.0 \\
Leukemia ( AML/CML/ALL & 17 & 24.3 \\
Multiple Myeloma & 3 & 4.3 \\
Myelodysplastic syndrome & 1 & 1.4 \\
Aplastic anemia & 1 & 1.4 \\
Testicular cancer & & \\
Type of transplant & & \\
Autologous & 46 & 65.7 \\
Allogeneic & 24 & 34.3 \\
Type of catheter & & \\
Hickman & 42 & 60.0 \\
Permcath & 24 & 34.3 \\
Port-a-cath & 4 & 5.7 \\
\hline
\end{tabular}

HL - Hodgkin's Lymphoma; NHL- Non-Hodgkin lymphoma, AML- Acute Myeloid Leukemia, CML- Chronic Myeloid Leukemia, ALL- Acute Lymphocytic Leukemia

The median of administered medication in $24 \mathrm{~h}$ was eight medications (varied from 4 to 16 ) while $53.9 \%$ of the sample received eight or more agents (Figure 1 ).

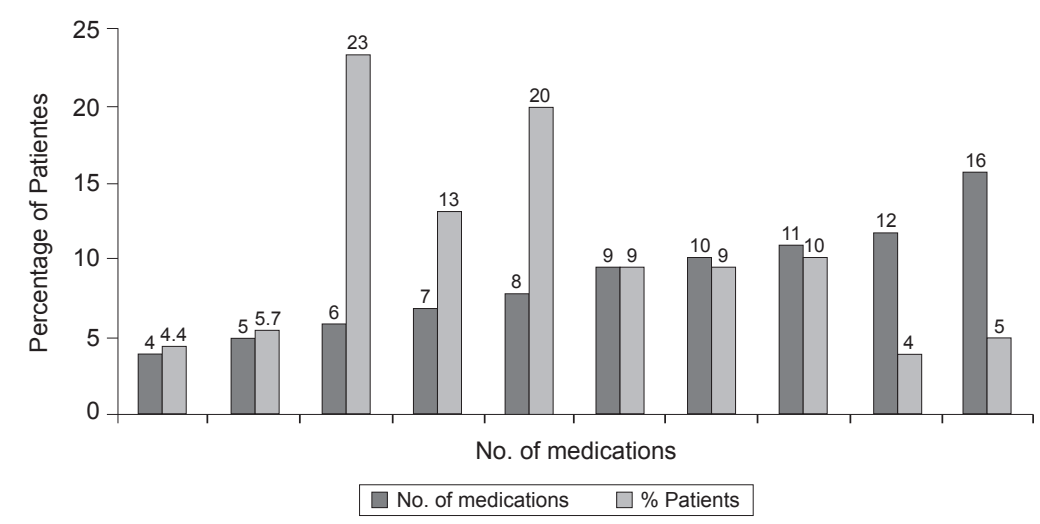

Figure 1 - Percentage of patients according to medication used in 24-hour period. São Paulo, SP, Brazil 2005

A total of 33 different drugs were identified in therapy, $27.3 \%$ of which were anti-microbial drugs. This class utilized by the sample included: acyclovir $(70 ; 100 \%)$, cefepime $(33 ; 47.1 \%)$, fluconazole $(32 ; 45.7 \%)$, teicoplanin $(7 ; 10 \%)$, ciprofloxacin $(1 ; 1.4 \%)$, levofloxacin $(7 ; 10 \%)$, meropenem $(3 ; 4.3 \%)$, sulfamethoxazole+trimethoprim $\quad(9 ; 12.9 \%) \quad$ and vancomycin $(1 ; 1.4 \%)$. Among these, $75 \% \quad(n=6)$ presented potentially interactive characteristics, which were examined in light of PDI. Hence, the analysis included fluconazole and ciprofloxacin and sulfamethoxazole+trimethoprim. Levofloxacin, vancomycin and teicoplanin did not present combinations that resulted in PDI. 
Considering the total number of used medications $(n=33), 32$ distinct PDIs were identified, while $71.4 \%$ $(n=50)$ of the sample presented at least one PDI. In the PDI analysis of anti-microbial medication, half of the patients $(n=35)$ were exposed to 13 PDIs. Of these, $53.8 \%$ occurred with fluconazole, $30.8 \%$ with ciprofloxacin and $15.4 \%$ due to the use of sulfamethoxazole+trimethoprim.

Among the patients using fluconazole $(n=32) 93.7 \%$ presented at least one PDI. Two PDIs were identified with the use of sulfamethoxazole+trimethoprim, which occurred in four different patients while four PDIs were observed in a single patient with the use of ciprofloxacin.

PDIs of anti-microbial medication were of a pharmacokinetic nature, $84.6 \%$ capable of modifying the pattern of metabolism, interfering in serum levels of the object-medication.

Most PDIs (92.3\%) presented moderate severity with scientific evidence originating from non-controlled studies $(53.8 \%)$, which could result in increased serum levels of the object-medication $(77.0 \%)$, with delayed effect time onset $(61.5 \%)$; the risk of mixed therapy involved implies the need to monitor serum levels and the toxicity of the agents involved (76.9\%) (Table 2 ).

Logistic regression indicated that being a man $(O R=2.4)$, between 40 and 49 years of age $(O R=6.1)$, and using four or more medications $(O R=6.9)$ significantly increased the risk of PDI (Table 3 ).

Table 2 - Description of potential drug interactions of anti-microbial medication. São Paulo, SP, Brazil 2005

\begin{tabular}{|c|c|c|c|c|c|c|c|}
\hline \multirow{2}{*}{ Potential Drug Interaction } & \multicolumn{2}{|c|}{ Cases $(n=70)$} & \multirow{2}{*}{ Severity * } & \multirow{2}{*}{$\begin{array}{l}\text { Scientific } \\
\text { evidence * }\end{array}$} & \multirow{2}{*}{ Clinical Implication * } & \multirow{2}{*}{ Onset * } & \multirow{2}{*}{$\begin{array}{c}\text { Risk of combined } \\
\text { therapy }{ }^{\dagger}\end{array}$} \\
\hline & $\mathbf{n}$ & $\%$ & & & & & \\
\hline Fluconazole+omeprazole & 28 & 40.0 & Moderate & Suspected & $\downarrow$ absorption of antifungal medications & Fast & $\mathrm{D}$ \\
\hline Fluconazole+diazepam & 13 & 18.5 & Moderate & Established & 个 Diazepam serum levels & Fast & C \\
\hline Fluconazole+cyclosporine & 11 & 15.7 & Moderate & Established & 个 cyclosporine serum levels & Delayed & C \\
\hline Fluconazole+dexamethasone & 10 & 14.2 & Moderate & Suspected & 个 corticosteroid serum levels & Delayed & C \\
\hline Fluconazole+phenytoin & 3 & 4.2 & Moderate & Likely & $\uparrow$ phenytoin serum levels & Delayed & $\mathrm{D}$ \\
\hline Fluconazole+sertraline & 2 & 2.8 & Moderate & NS & $\uparrow$ sertraline serum levels & NS & C \\
\hline $\begin{array}{l}\text { Sulfamethoxazole }+ \text { trimethoprim } \\
+ \text { cyclosporine }\end{array}$ & 2 & 2.8 & Moderate & Suspected & $\Downarrow$ cyclosporine serum levels & Delayed & C \\
\hline $\begin{array}{l}\text { Sulfamethoxazole+trimethoprim+ } \\
\text { phenytoin }\end{array}$ & 2 & 2.8 & Moderate & Likely & 个 phenytoin serum levels & Delayed & $\mathrm{C}$ \\
\hline Ciprofloxacin + cyclophosphamide & 1 & 1.4 & Moderate & Possible & $\Downarrow$ antimicrobial effect & Delayed & C \\
\hline Ciprofloxacin + cyclosporine & 1 & 1.4 & Moderate & Suspected & $\uparrow$ cyclosporine serum levels & Delayed & C \\
\hline Ciprofloxacin + dexamethasone & 1 & 1.4 & Moderate & NS & $\uparrow$ excretion of both & $\mathrm{NE}$ & C \\
\hline Ciprofloxacin +diazepam & 1 & 1.4 & Minor & Possible & 个 diazepam serum levels & Delayed & C \\
\hline Fluconazole+ cyclophosphamide & 1 & 1.4 & Moderate & NS & 个 cyclophosphamide serum levels & NE & C \\
\hline
\end{tabular}

* Drug Interaction Facts ${ }^{(3)} ;{ }^{\dagger}$ Drug Interaction Handbook ${ }^{(4)} ; \mathrm{NS}-$ not specified; $\uparrow=$ Increase $\vee=$ Decrease

Table 3 - Association among potential drug interactions and clinical-demographic variables. São Paulo, SP, Brazil 2005

\begin{tabular}{lcc}
\hline \multicolumn{1}{c}{ Variables } & Odds Ratio * $(\mathrm{Cl}-95 \%)$ & $\boldsymbol{p}$ \\
\hline $\begin{array}{l}\text { Gender } \\
\text { Female } \\
\text { Male }\end{array}$ & 1.00 & \\
Age & $2.412(2.013-2.887)$ & $<0.001$ \\
$\leq 19$ & 1.00 & \\
$20-29$ & $0.977(0.634-1.506)$ & 0.917 \\
$30-39$ & $1.541(0.993-2.392)$ & 0.054 \\
$40-49$ & $6.176(4.008-9.516)$ & $<0.001$ \\
$\geq 50$ & $1.616(1.096-2.382)$ & 0.015 \\
Type of transplant & 1.00 & \\
Autologous & $0.826(0.664-1.028)$ & 0.087 \\
Allogenic & 1.00 & \\
Number of drugs & $6.951(5.561-8.687)$ & $<0.001$ \\
$<4$ & & \\
$\geq 4$ &
\end{tabular}

\section{Discussion}

Patients undergoing HSCT were particularly susceptible to PDIs, not only due to their clinical particularities but also due to their pharmacological therapy profiles composed of various medications, many with potentially interactive characteristics, which were implicated in many important DIs. As indicated in previous studies, they could harm patients $(7,14)$. However, it is possible that the effects accruing from PDIs pass unnoticed in these patients or are interpreted as manifestations of a disease's clinical development because of their condition's complexity.

The relationship between the number of medications and DIs was well documented in the literature by various authors ${ }^{(8-9,11,14-15)}$. This study revealed that the chances of a PDI occurring was almost seven times greater $(\mathrm{OR}-=6.9)$ when the patient used four or more medications. A recent 
study conducted in an intensive therapy unit reported a positive association between the number of medications and potential interactions on the patient's sixth day of hospitalization $^{(15)}$. Oncologic studies addressing different contexts concluded that the number of medications was also a predictive factor for DIs ${ }^{(8-9,11)}$. Regardless of the investigation's context, these authors analyzed clinically chronic $^{(8-9,11)}$ and severely acute ${ }^{(15)}$ patients. Hence, the complexity of the therapy is closely related to the risk of PDIs, whether these are mild or severe.

Being between 40 to 49 years old was also a factor associated with PDIs. However, being within the older ages in the different age ranges (30-39 years old, $O R=1.54$ and 50 years old or older, $O R=1.61$ ) was an indicator of risk for PDIs, even though for those between 30 and 39 years old no statistically significant difference $(p=0.054)$ was found for the level of significance at $5 \%$. It is possible that this result being close to the rejection limit is due to the sample size. Even though these individuals were not included in the most vulnerable group, it is known that renal structural changes occur with aging and these can have an impact on the excretion of medication, increasing toxicity of co-administered medications and chances of PDI. It is estimated that weight and renal volume reduce from $20 \%$ to $30 \%$ between 30 and 90 years of age, the number of glomeruli is reduced $30 \%$ to $50 \%$ and renal plasma flow reduces more than $600 \mathrm{ml} / \mathrm{min}$ at 30 years of age and up to $300 \mathrm{~m} / \mathrm{min}$ at 80 years of age ${ }^{(16)}$.

There was no statistically significant association in relation to the type of HSCT. Although empirical observation has shown that allogeneic HSCT seems to have a greater tendency to develop PDIs given the use of cyclosporine. It was the only medication involved in all PDIs with anti-microbial medications, which is mandatory in this kind of transplantation and used in all the studied patients.

Fluconazole was the agent most frequently involved in PDIs, certainly due to two aspects: it was the anti-microbial medication most prescribed in the studied sample (45.7\%) and is an enzymatic inhibitor of the cytochrome system P450 (CYP450) of isoenzymes CYP2C8/9, CYP2C19 and CYP3A4 responsible for metabolizing various medications used in $\operatorname{HSCT}^{(3-4,7,10)}$.

Most of the PDIs could increase the serum levels of the object medication, especially cyclosporine, since this immunosuppressive drug was involved in PDIs with three antimicrobial medications. Even though the object agent is the same in each PDI, the clinical implication depends on the effect caused by precipitants (fluconazole, ciprofloxacin, and sulfamethoxazole+trimethoprim).
Cyclosporine is a substrate of the isoenzyme CYP3A4 and its co-administration with fluconazole tends to increase the pharmacological effects and toxicity of the immunosuppressant drug evidenced through nephrotoxicity, cholestasis or paresthesias ${ }^{(3-4)}$. Hence, even though toxicity was not assessed, almost half of the patients undergoing allogeneic HSCT $(n=24)$ were exposed to this PDI. In a previous study, this DI was also identified in patients treated with antifungal drugs ${ }^{(17)}$.

Sulfamethoxazole+trimethoprim was prescribed to HSCT patients at the beginning of the conditioning phase as prophylaxis for Pneumocistis carinii and the therapy was interrupted on day 1 . However, cyclosporine was introduced on day 1 , a situation that certainly predisposes one to PDIs, and may increase nephrotoxicity and the risk of graft rejection ${ }^{(3-4,13)}$. The enzymatic inhibition process triggered by sulfamethoxazole+trimethoprim is slow and even if it is suspended on day 1 , the effects accruing from the PDI should be carefully monitored, especially on those patients with nephrotoxicity ${ }^{(3-4,7,13,18)}$..

In relation to the PDI ciprofloxacin+cyclosporine, a case report of a patient with bone marrow aplasia showed that the mixed therapy resulted in increased immunosuppressive serum levels, though with no severe consequences occurred due to the timeliness in adjusting the drug dosage ${ }^{(19)}$.

The onset time of interactions was delayed in most cases $(61.5 \%)$, which is an additional reason to monitor patients during the entire follow-up period (at hospitals and outpatient clinics). Even though some medications used at the beginning of medullar conditioning are suspended for the introduction of others, the pharmacological mechanisms that involve PDIs are delayed, and can take from days to weeks, so that the signs and symptoms may remain hidden in the pre HSCT phase, though subject to appear post operative. Such a fact may put at risk the success of the therapy if we consider that the number of medications used in neutropenia (post HSCT) is even larger, which increases the risk of PDIs. This is especially so when enzymatic inhibitors are used.

Even though more than half of PDIs were noted based on scientific evidence that came from non-controlled studies, these originated from information bases respected in the scientific milieu. The Drug Interaction Facts ${ }^{(3)}$ was considered to be highly accurate when compared to other PDI screening sources, with a sensitivity of specificity of $97 \%{ }^{(20)}$. Also the author of this compendium is one of the main information sources concerning DIs, hence it is used in various studies ${ }^{(8-9,11,14)}$. 
In relation to the risk of mixed therapies, we verified that, with the exception of two PDIs, fluconazole+omeprazole and fluconazole+phenytoin, the remaining were classified as $\mathrm{C}$, that is, a recommendation to monitor the therapy. From a practical point of view, the activity "monitor therapy" should to be shared among different professionals, e.g. physicians, pharmacists and nurses. The latter should know the clinical manifestations that accrue from PDIs so they can guide the nursing staff in how to search for warning signs, especially in the field of oncology, in which patients are frequently exposed to complex therapeutic regimes. Additionally, it is essential that measures aimed to reduce the risk and management of PDIs are implemented, including: the use of DI tables in the hospitalization units; electronic prescriptions with DI alerts; dosage adjustments based on serum levels, especially of object-medication; schedules based on the pharmacokinetics characteristics of the combined medications on the part of the nursing staff; and change therapy when the classification of the risk of therapy is either $\mathrm{D}$ or $\mathrm{X}^{(4)}$.

This study was a pioneer in the investigation of this theme in the context of oncologic nursing, in addition to bringing information concerning PDIs, the level of risk in the case of mixed therapies, variables that can support clinical practice by indicating actions to be implemented by professionals, especially in relation to the inclusion of specific items in nursing prescription. PDIs were identified based on Drug Interaction Facts, a reference used in various studies, which enables comparisons with future investigations. However, there are limitations that deserve to be noted so they can be appropriately handled in future studies. Even though the sample was limited to a single facility, the therapeutic protocols reflect the current practice of therapy. Data were collected on day 1 and excluded the possibility of identifying other PDIs, since once a patient is in the post HSCT phase, the regimen becomes even more complex. The PDI analysis included only the potentially interactive anti-microbial medications, an aspect that certainly led to an underestimated occurrence of PDIs. Finally, the PDI outcomes were not evaluated, but only the risk of patients to be exposed to a PDI.

\section{Conclusion}

PDIs involving the anti-microbial drugs fluconazole, ciprofloxacin and sulfamethoxazole+trimethoprim predominantly presented moderate severity. Even then alterations of medications' serum levels are indicated due to potential clinical implications, especially for cyclosporine, which can lead to adverse outcomes such as graft rejection (reduced serum levels) and nephrotoxicity (increased serum levels). These are delayed effects but they can have an impact on the morbidity and mortality of patients undergoing HSTC. Evidence concerning PDIs originate from non-controlled studies that do not refer to essential clinical studies or controlled studies that could corroborate or refute data obtained from case reports. However, the combined therapy utilizing anti-microbial drugs and object-medication such as cyclosporine, essential in allogeneic HSCT, can be safe if professionals share responsibility in relation to the control of serum levels of such agents. Among other factors, responsibility may include a possible dosage adjustment and rigorous monitoring of effects that accrue from PDIs, especially for individuals in risk groups, such as being older than 30 years of age and using four or more medication.

\section{References}

1. Kohler GI, Bode-Borger SM, Busse R, Hoopmann M, Welte $\mathrm{T}$, Böger $\mathrm{RH}$. Drug-drug interactions in medical patients: effects on in-hospital treatment and relation to multiple drug use. Int J Clin Pharmacol Ther. 2000;38(11):504-13.

2. Kuhlmann J, Mück W. Clinical pharmacological strategies to assess drug interactions potential during drug development. Drug Saf. 2001;24(10):715-25.

3. Tatro DS. Drug interactions facts. Saint Louis: Facts and Comparisons; 2002.

4. Bachmann KA. Drug interactions handbook. Hudson: Lexi-Comp; 2003.

5. Soubani AO. Critical care considerations of hematopoietic stem cell transplantation. Crit Care Med. 2006;34(9 Suppl):S251-67.

6. Blower P, de Wit R, Goodin S, Aapro M. Drug-drug interactions in oncology: why are they important and can they be minimized? Crit Rev Oncol Hematol. 2005;55(2):117-42.

7. Egger SS, Méier S, Leu C, Christen S, Gratwohl A, Krähenbühl $S$, et al. Drug interactions and adverse events associated with antimycotic drugs used for invasive aspergllosis in hematopoietic SCT. Bone Marrow Transplant. 2009; 1-7. [Epub ahead of print] doi: 10.1038/bmt.2009.325.

8. Riechelmann RP, Tannock IF, Wang L, Saad ED, Taback NA, Krzyzanowska MK. Potential drug interaction and duplicate prescriptions among cancer patients. J Nat Cancer Inst. 2007;99(8):592-600. 
9. Riechelmann RP, Zimmermann C, Chin SN, Wang L, O'Carroll A, Zarinehbaf S, et al. Potential drug interactions in cancer patients receiving supportive care exclusively. J Pain Symptom Manage. 2008;35(5):535-43.

10. Secoli SR, Padilha KG. Polifarmácia em leucemia mielóide aguda: administração e interação de medicamentos. Prática Hosp. 2005;7(17):78-85.

11. Riechelmann RP, Moreira F, Smaletz O, Saad ED. Potential for drug interactions in hospitalized patients. Cancer Chemother Pharmacol. 2005;56(3):286-90.

12. Buajordet I, Ebbesen J, Erikssen J, Brørs O, Hilberg T. Fatal adverse drug events: the paradox of drug treatment. J Inter Med. 2001;250(4):327-41.

13. Campana C, Regazzi MB, Buggia I, Molinaro M. Clinically significant drug interactions with cyclosporin. An update. Clin Pharmacokinet. 1996;30(2):141-79.

14. Fonseca RB, Secoli SR. Medicamentos utilizados em transplante de medula óssea: um estudo sobre combinações dos antimicrobianos potencialmente interativos. Rev Esc Enferm USP. 2008;42(4):706-14.

15. Lima REF, Cassiani SH. Potential drug interactions in intensive care patients at a teaching hospital. Rev. Latino-Am. Enfermagem. 2009;17(2):222-7.

16. Abreu PF, Sesso RCC, Ramos LR. Aspectos renais no idoso. J Bras Nefrol. 1998;20(2):158-65.

17. Depont F, Vargas F, Dutronc $H$, Giauque E, Ragnaud JM, Galpérine T, et al. Drug-drug interaction with systemic antifungals in clinical practice. Pharmacolepidemiol Drug Saf. 2007;16(11):1227-33.

18. Bartynski WS, Zeigler ZR, Shadduck RK, Lister J. Pretransplantation conditioning influence on the occurrence of cyclosporine or FK-506 neurotoxicity in allogeneic bone marrow transplantation. AJNR Am J Neuroradiol. 2004;25(2):261-9.

19. Borras-Blasco J, Conesa-Garcia V, Navarro-Ruiz A, Marín-Jiménez F, González-Delgado M, Gomez-Corrons A. Ciprofloxacin, but not levofloxacin, affests cyclosporine levels in a patient with pure red blood cell aplasia. Am J Med Sci. 2005;330(3):144-6.

20. Barrons R. Evaluation of personal digital assistant software for drug interactions. Am J Health Syst Pharm. 2004;61(4):380-5. 